\section{Targeted capture and massively parallel sequencing in pediatric cardiomyopathy: development of novel diagnostics}

\author{
Muhammad Tariq, ${ }^{1}$ Thanh-Tam Le, ${ }^{1}$ \\ Patrick Putnam, ${ }^{2}$ Steven Kindel, \\ Mehdi Keddache, ${ }^{2}$ Stephanie M. Ware ${ }^{1,2}$ \\ 'Division of Molecular Cardiovascular \\ Biology, ${ }^{2}$ Division of Human Genetics, \\ Cincinnati Children's Hospital Medical \\ Center and University of Cincinnati \\ College of Medicine, Cincinnati, OH, USA
}

\section{Abstract}

Pediatric cardiomyopathy is a genetically heterogeneous disease associated with significant morbidity. Although identification of underlying etiology is important for management, therapy, and screening of at risk family members, molecular diagnosis is difficult due to the large number of causative genes, the high rate of private mutations, and cost. In this study, we aimed to define the genetic basis of pediatric cardiomyopathy and test a novel diagnostic tool using a custom targeted microarray coupled to massively parallel sequencing. Three patients with cardiomyopathy were screened using a custom NimbleGen sequence capture array containing 110 genes and providing $99.9 \%$ coverage of the exons of interest. The sensitivity and specificity was over $99 \%$ as determined by comparison to long-range polymerase chain reaction (PCR)based massively parallel sequencing, Sanger sequencing of missense variants, and single nucleotide polymorphisms genotyping using the Illumina Infinium Omnil array. Overall, 99.73\% of the targeted regions were captured and sequenced at over $10 \mathrm{x}$ coverage, allowing reliable mutation calling in all patients. Analysis identified a total of 165 non-synonymous coding single nucleotide polymorphisms (cSNPs) of which 89 were unique and 14 were novel. On average, each patient had $4 \mathrm{cSNPs}$ predicted to be pathogenic. In conclusion, we report a cardiomyopathy sequencing array that allows simultaneous assessment of 110 genes. Comparison of targeted sequence capture versus PCR-based enrichment methods demonstrates that the former is more sensitive and efficient. Array-based sequence capture technology followed by massively parallel sequencing is promising as a robust and comprehensive tool for genetic screening of cardiomyopathy. These results provide important information about genetic architecture and indicate that improved annotation of variants and interpretation of clinical significance, particularly in cases with multiple rare variants, are important for clinical practice.

\section{Introduction}

Pediatric cardiomyopathies are clinically heterogeneous disorders of heart muscle that are responsible for significant morbidity and mortality. The primary cause of the majority of cases of pediatric cardiomyopathy is genetic. To date, more than 100 genes have been implicated in cardiomyopathy, but comprehensive genetic diagnosis has been problematic because of the large number of genes and private nature of mutations.

In the last two decades, polymerase chain reaction (PCR)-based enrichment of genomic DNA has been the dominant technique for targeted enrichment of specific genomic regions. Massively parallel (Next-Generation) sequencing has recently emerged as a powerful tool for sequencing utilizing PCR-based genomic enrichment. However, the high throughput benefits of massively parallel sequencing remain limited by the relatively labor intensive nature of PCR-based enrichment. As a result, novel non-PCR based enrichment procedures have emerged as promising alternatives. ${ }^{1}$ Microarray-based sequence capture hybridization (SeqCap) uses a chip arrayed with specific probes and allows enrichment of multiple dispersed segments or long single genome segments. ${ }^{2-4}$ Recently, this approach has been shown to be successful in identifying novel genes involved in inherited human monogenic (recessive or dominant) disorders ${ }^{5-8}$ or polymorphic genetic variants associated with complex human diseases. ${ }^{9,10}$ While these approaches have been proven to be useful in researchbased testing, it is not clear whether these platforms are suitable for the higher stringency required for clinical molecular testing. In the present study, we applied a customized array-based SeqCap enrichment strategy coupled to massively parallel sequencing and successfully screened 110 genes in cardiomyopathy patients in a single sequencing run each and identified mutations associated with disease. We have evaluated the performance and quality of long-range PCR (LR-PCR) versus SeqCap enrichment methods using cardiomyopathy as a disease model. The results indicate that this is a promising platform for clinical diagnostics and provide important information about the complexity of the genetic architecture in this disease.

\section{Materials and Methods}

\section{Patients and DNA samples}

Three cardiomyopathy patients, CM0001, CM0002 (Pedigree A, Figure 1) and CM0006 (Pedigree B, Figure 1) were studied. The patients underwent clinical evaluation by a
Correspondence: Stephanie Ware, Cincinnati Children's Hospital Medical Center, 240 Albert Sabin Way, MLC 7020, Cincinnati, OH 45229, USA.

Tel. +513.636.9427 - Fax: +513.636-5958.

E-mail: stephanie.ware@cchmc.org

Key words: sequence capture, massively parallel sequencing, restrictive cardiomyopathy, desmin, missense mutation.

Acknowledgments: we thank the patients for their participation. We acknowledge the technical contribution of Anup Tilak. This study was supported by funding from the Children's Cardiomyopathy Foundation and Cincinnati Children's Hospital's Clinical and Translational Science Award NIH-ULIRR026314.

Contributions: MT and TL performed experiments; PP and MK performed sequence alignment of massively parallel sequencing data to RefSeq; PP and SMW performed statistical analysis; MT performed bioinformatic and mutational analysis, and Sanger validation; SK and SMW performed clinical diagnosis; MT and SMW wrote manuscript; SMW designed the project and received funding. All authors read and approved the final manuscript.

Conflict of interests: the authors have no conflict of interests.

Received for publication: 1 October 2011.

Revision received: 15 April 2012.

Accepted for publication: 17 April 2012

This work is licensed under a Creative Commons Attribution NonCommercial 3.0 License (CC BYNC 3.0).

(C) Copyright M. Tariq et al., 2012

Licensee PAGEPress, Italy

Cardiogenetics 2012; 2:e7

doi:10.4081/cardiogenetics.2012.e7

pediatric geneticist and pediatric cardiologist at Cincinnati Children's Hospital Medical Center (CCHMC). Written informed consent was obtained from the parents or study participants prior to initiation. This study design was approved by the CCHMC Institutional Review Board. Genomic DNA was extracted using a Qiagen purification kit (Puregene Blood Case kit C, QIAGEN Sciences, Maryland, USA). DNA quality and quantity were calculated with a NanoDrop spectrophotometer (ThermoScientific).

\section{Selection of candidate genes}

One hundred and ten nuclear genes were selected for analysis with microarray-based targeted SeqCap. Of these, a smaller subset of 31 genes was chosen for PCR-based enrichment (Table 1). Genes available on commercially available panels for cardiomyopathy at 
Table 1. Cardiomyopathy custom array gene content.

\begin{tabular}{|c|c|c|c|c|c|}
\hline $\begin{array}{l}\text { Genes targeted by capture } \\
\text { array enrichment }\end{array}$ & $\begin{array}{l}\text { Total coding } \\
\text { exons }\end{array}$ & $\begin{array}{c}\text { Encoded } \\
\text { protien (AA) }\end{array}$ & $\begin{array}{l}\text { Targeted sequence (bp) on } \\
\text { capture custom array }\end{array}$ & $\begin{array}{l}\text { NCBI GenBank } \\
\text { accession \# }\end{array}$ & $\begin{array}{l}\text { Chromosomal } \\
\text { location }\end{array}$ \\
\hline $\begin{array}{l}\text { Sarcomere } \\
\text { MYH7* } \\
\text { MYBPC3* } \\
\text { TNNT2* }^{*} \\
\text { TPM1* }^{*} \\
\text { MYL3* } \\
\text { MYL2* } \\
\text { ACTC1* } \\
\text { TNNI }^{*} \\
\text { MYH6* } \\
\text { TNNC1 }\end{array}$ & $\begin{array}{c}38 \\
33 \\
15 \\
9 \\
6 \\
7 \\
6 \\
6 \\
37 \\
6\end{array}$ & $\begin{array}{l}1935 \\
1274 \\
295 \\
284 \\
195 \\
166 \\
377 \\
210 \\
1939 \\
161\end{array}$ & $\begin{array}{l}9419 \\
7035 \\
3517 \\
2285 \\
1093 \\
1512 \\
1609 \\
1785 \\
8949 \\
1455\end{array}$ & $\begin{array}{l}\text { NG_007884 } \\
\text { NG_007667 } \\
\text { NG_007556 } \\
\text { NG_007557 } \\
\text { NG_007555 } \\
\text { NG_007554 } \\
\text { NG_007553 } \\
\text { NG_007866 } \\
\text { NC_000014 } \\
\text { NG_008963 }\end{array}$ & $\begin{array}{c}14 \mathrm{q} 11.2 \\
11 \mathrm{p} 11.2 \\
1 \mathrm{q} 32.1 \\
15 \mathrm{q} 22.2 \\
3 \mathrm{q} 21.31 \\
12 \mathrm{q} 24.11 \\
15 \mathrm{q} 14 \\
19 \mathrm{q} 13.4 \\
14 \mathrm{q} 11.2 \\
3 \mathrm{p} 21.1\end{array}$ \\
\hline $\begin{array}{l}\text { Fatty acid oxidation } \\
\text { ACADVL } \\
\text { HADHA }(\alpha) \\
H A D H A(\beta) \\
\text { ACADM }\end{array}$ & $\begin{array}{l}19 \\
20 \\
15 \\
12\end{array}$ & $\begin{array}{l}633 \\
763 \\
474 \\
421 \\
\end{array}$ & $\begin{array}{l}1967 \\
4680 \\
3265 \\
3047\end{array}$ & $\begin{array}{l}\text { NG_007975 } \\
\text { NG_007121 } \\
\text { NG_007294 } \\
\text { NG_007045 }\end{array}$ & $\begin{array}{l}13 p 13.1 \\
2 \mathrm{p} 23.3 \\
2 \mathrm{p} 23.3 \\
1 \mathrm{p} 31.1\end{array}$ \\
\hline $\begin{array}{l}\text { Carnitine transport } \\
\text { SLC22A5/0CTN2* } \\
\text { CPT2 } \\
\text { CPT1A } \\
\text { SLC25A20 }\end{array}$ & $\begin{array}{c}10 \\
5 \\
18 \\
9\end{array}$ & $\begin{array}{l}557 \\
658 \\
773 \\
301\end{array}$ & $\begin{array}{l}2761 \\
2331 \\
4536 \\
2266\end{array}$ & $\begin{array}{l}\text { NG_008982 } \\
\text { NG_008035 } \\
\text { NG_011801 } \\
\text { NG_008171 }\end{array}$ & $\begin{array}{c}5 q 31.1 \\
1 \mathrm{p} 32.3 \\
11 q 13.3 \\
3 p 21.31\end{array}$ \\
\hline $\begin{array}{l}\text { Storage disorder } \\
\text { GAA } \\
\text { GANC } \\
\text { LAMP-2* } \\
\text { PRKAG2* } \\
\text { GBE1 } \\
\text { GLA } \\
\text { PHKA2 } \\
\text { AGL } \\
\text { NAGA } \\
\text { PYGM }\end{array}$ & $\begin{array}{c}19 \\
24 \\
9 \\
16 \\
16 \\
7 \\
33 \\
33 \\
9 \\
20 \\
\end{array}$ & $\begin{array}{c}952 \\
914 \\
411 \\
569 \\
702 \\
429 \\
1235 \\
1532 \\
411 \\
842\end{array}$ & $\begin{array}{l}4613 \\
4623 \\
2276 \\
4080 \\
4022 \\
1911 \\
8124 \\
7690 \\
2250 \\
4345\end{array}$ & $\begin{array}{c}\text { NG_009822 } \\
\text { NM_198141.2 } \\
\text { NG_007995 } \\
\text { NG_007486 } \\
\text { NG_011810 } \\
\text { NG_007119 } \\
\text { NG_016622 } \\
\text { NG_012865 } \\
\text { NG_009247 } \\
\text { NG_013018 }\end{array}$ & $\begin{array}{c}17 q 25.3 \\
15 q 15.1 \\
X q 24 \\
7 q 36.1 \\
3 p 12.2 \\
X q 22.1 \\
X p 12.13 \\
1 p 21.2 \\
22 q 13.2 \\
11 q 13.1 \\
\end{array}$ \\
\hline $\begin{array}{l}\text { Metabolic } \\
\text { HMGCL } \\
\text { PMM2 } \\
\text { D2HGD } \\
\text { MLYCD }\end{array}$ & $\begin{array}{l}9 \\
8 \\
9 \\
5\end{array}$ & $\begin{array}{l}325 \\
246 \\
521 \\
493\end{array}$ & $\begin{array}{l}2023 \\
2011 \\
2361 \\
1852\end{array}$ & $\begin{array}{l}\text { NG_013061 } \\
\text { NG_009209 } \\
\text { NG_012012 } \\
\text { NG_009079 }\end{array}$ & $\begin{array}{c}1 \mathrm{p} 36.11 \\
16 \mathrm{p} 13.2 \\
2 \mathrm{q} 37.3 \\
16 \mathrm{q} 23.3\end{array}$ \\
\hline $\begin{array}{l}\text { Desmosome } \\
\text { JUP } \\
\text { DSP } \\
\text { PKP2 } \\
\text { DSG2 } \\
\text { DSC2 }\end{array}$ & $\begin{array}{c}9 \\
24 \\
14 \\
15 \\
16\end{array}$ & $\begin{array}{c}563 \\
2871 \\
881 \\
1118 \\
901\end{array}$ & $\begin{array}{c}3160 \\
11112 \\
3826 \\
4617 \\
4068\end{array}$ & $\begin{array}{l}\text { NG_009090 } \\
\text { NG_008803 } \\
\text { NG_009000 } \\
\text { NG_007072 } \\
\text { NG_008208 }\end{array}$ & $\begin{array}{c}17 q 21.2 \\
6 p 24.3 \\
12 p 11.21 \\
18 q 12.1 \\
18 q 12.1\end{array}$ \\
\hline $\begin{array}{l}\text { Cytoskeleton, Z-disc etc } \\
\text { ACTN2 } \\
\text { DES* } \\
\text { MYOZ2 } \\
\text { LDB3* } \\
\text { CSRP3* } \\
\text { TCAP* } \\
\text { SGCB } \\
\text { SGCD } \\
\text { TTN } \\
\text { DMD } \\
\text { MYPN* } \\
\text { PLN* } \\
\text { VCL(meta) } \\
\text { CRYAB* } \\
\text { CAV3 } \\
\text { DTNA } \\
\text { SNTA1 }\end{array}$ & $\begin{array}{c}21 \\
9 \\
5 \\
13 \\
5 \\
2 \\
6 \\
8 \\
311 \\
79 \\
19 \\
1 \\
22 \\
3 \\
2 \\
21 \\
8\end{array}$ & $\begin{array}{c}894 \\
470 \\
264 \\
732 \\
194 \\
167 \\
318 \\
290 \\
33423 \\
3385 \\
1320 \\
52 \\
1134 \\
175 \\
151 \\
743 \\
505\end{array}$ & $\begin{array}{c}5264 \\
2279 \\
1260 \\
3619 \\
1265 \\
664 \\
1509 \\
2019 \\
123375 \\
9800 \\
5933 \\
250 \\
5524 \\
758 \\
612 \\
5250 \\
1989\end{array}$ & $\begin{array}{c}\text { NG_009081 } \\
\text { NG_008043 } \\
\text { NM_016599.3 } \\
\text { NG_008876 } \\
\text { NG_011932 } \\
\text { NG_008892 } \\
\text { NG_008891 } \\
\text { NG_008693 } \\
\text { NG_011618 } \\
\text { NG_012232.1 } \\
\text { NM_032578.2 } \\
\text { NG_009082 } \\
\text { NG_008868 } \\
\text { NG_009824 } \\
\text { NG_008797 } \\
\text { NG_009201 } \\
\text { NG_011622 }\end{array}$ & $\begin{array}{c}1 \mathrm{q} 43 \\
2 \mathrm{q} 35 \\
4 \mathrm{q} 26 \\
10 \mathrm{q} 23.2 \\
11 \mathrm{p} 15.1 \\
17 \mathrm{q} 12 \\
4 \mathrm{q} 12 \\
5 \mathrm{q} 33.3 \\
2 \mathrm{q} 31.2 \\
x p 21 \\
10 \mathrm{q} 21.3 \\
6 \mathrm{q} 22.31 \\
10 \mathrm{q} 22.2 \\
11 \mathrm{q} 23.1 \\
3 \mathrm{p} 25.3 \\
18 \mathrm{q} 12.1 \\
20 \mathrm{q} 11.21\end{array}$ \\
\hline
\end{tabular}


Continued from previous page.

\begin{tabular}{|c|c|c|c|c|c|}
\hline $\begin{array}{l}\text { Genes targeted by capture } \\
\text { array enrichment }\end{array}$ & $\begin{array}{l}\text { Total coding } \\
\text { exons }\end{array}$ & $\begin{array}{c}\text { Encoded } \\
\text { protien (AA) }\end{array}$ & $\begin{array}{l}\text { Targeted sequence (bp) on } \\
\text { capture custom array }\end{array}$ & $\begin{array}{l}\text { NCBI GenBank } \\
\text { accession \# }\end{array}$ & $\begin{array}{l}\text { Chromosomal } \\
\text { location }\end{array}$ \\
\hline \multicolumn{6}{|l|}{ Syndromic } \\
\hline$T A Z^{*}$ & 11 & 292 & 1896 & NG_009634 & $\mathrm{Xq} 28$ \\
\hline ALMS1 & 23 & 4169 & 4566 & NG_011690 & 2p13.1 \\
\hline PTPN11 & 15 & 593 & 3654 & NG 007459 & $12 \mathrm{q} 24.13$ \\
\hline$H R A S$ & 4 & 189 & 919 & NG_007666 & $11 \mathrm{p} 15.5$ \\
\hline KRAS & 4 & 189 & 1001 & NG_007524 & $12 \mathrm{p} 12.1$ \\
\hline SOS1 & 23 & 1333 & 6332 & NG_007530 & $2 \mathrm{p} 22.1$ \\
\hline$B R A F$ & 18 & 766 & 4563 & NG_007873 & $7 \mathrm{q} 34$ \\
\hline MEK1(MAP2K1) & 11 & 393 & 2762 & NG_008305 & $15 q 22.31$ \\
\hline MEK2 or MAP2K2 & 11 & 400 & 2548 & NG_007996 & $19 \mathrm{p} 13.3$ \\
\hline$R A F 1^{*}$ & 16 & 648 & 3886 & NG_007467 & $3 \mathrm{p} 25.2$ \\
\hline \multicolumn{6}{|l|}{ Mitochondrial } \\
\hline $\mathrm{SCO} 2 *$ & 1 & 266 & 821 & NG_016235 & $22 q 13.33$ \\
\hline SURFI* & 9 & 300 & 1413 & NG_008477 & $9 \mathrm{q} 34.2$ \\
\hline COX10 & 7 & 443 & 2026 & NG_008034 & $17 \mathrm{p} 12$ \\
\hline COX17* & 2 & 63 & 502 & NM_005694 & $3 q 13.33$ \\
\hline COX15 & 9 & 410 & 2379 & NG_008986 & $10 \mathrm{q} 24.2$ \\
\hline$T K 2^{*}$ & 10 & 307 & 2508 & NG_016862 & $16 \mathrm{q} 21$ \\
\hline$D G K(D G U O K)^{*}$ & 7 & 277 & 1764 & NG_008044 & $2 \mathrm{p} 13.1$ \\
\hline FXN & 5 & 210 & 1258 & NG_008845 & $9 \mathrm{q} 21.11$ \\
\hline ANT1 (SLC25A4)* & 4 & 298 & 1262 & NG_013001 & $4 \mathrm{q} 35.1$ \\
\hline SLC25A3 & 7 & 362 & 1638 & NG_011702 & $12 \mathrm{q} 23.1$ \\
\hline SOD2* & 5 & 222 & 1277 & NG_008729 & $6 \mathrm{q} 25.3$ \\
\hline TSFM $^{*}$ & 7 & 346 & 1929 & NG_016971 & $12 q 14.1$ \\
\hline NDUFV2 & 8 & 249 & 1750 & NG_013355 & 18 p11.22 \\
\hline NDUFA11* & 4 & 228 & 1000 & NM_001193375 & $19 p 13.3$ \\
\hline DNAJC19 & 6 & 116 & 1252 & NG_022933 & $3 \mathrm{q} 26.33$ \\
\hline NDUFS8* & 6 & 210 & 992 & NG_017040 & $11 q 13.2$ \\
\hline NDUFS2 & 14 & 463 & 3131 & NG_013352 & $1 \mathrm{q} 23.3$ \\
\hline NDUFS6 & 4 & 124 & 1000 & NG_013354 & $5 p 15.33$ \\
\hline C60RF66 & 3 & 175 & 808 & NG_013379 & 6q16.1 \\
\hline \multicolumn{6}{|l|}{ Miscellaneous } \\
\hline EYA4 & 19 & 639 & 4545 & NG_011596 & $6 \mathrm{q} 23.2$ \\
\hline$L M N A^{*}$ & 12 & 664 & 3218 & NG_008692 & lq22 \\
\hline EMD & 6 & 254 & 1270 & NG_008677 & Xq28 \\
\hline TMPO & 4 & 694 & 2190 & NG_021393 & $12 \mathrm{q} 23.1$ \\
\hline PSEN1 & 10 & 467 & 2527 & NG_007386 & $14 \mathrm{q} 24.2$ \\
\hline PSEN2 & 10 & 448 & 2507 & NG_007381 & $1 \mathrm{q} 42.13$ \\
\hline RYR2 & 105 & 4967 & 28213 & NG_008799 & 1943 \\
\hline$A B C C 9$ & 38 & 1549 & 9432 & NG_012819. & $12 \mathrm{p} 12.1$ \\
\hline SCN5A & 27 & 2015 & 8377 & NG_008934 & $3 \mathrm{p} 22.2$ \\
\hline TGFB3 & 7 & 412 & 1872 & NG_011715 & $14 \mathrm{q} 24.3$ \\
\hline FKTN & 9 & 461 & 2278 & NG 008754 & $9 \mathrm{q} 31.2$ \\
\hline MYO6 & 34 & 1285 & 8320 & NG_009934 & $6 \mathrm{q} 14.1$ \\
\hline TMEM43 & 12 & 400 & 3000 & NG_008975 & $3 \mathrm{p} 25.1$ \\
\hline CMYAI/XIRPI & 1 & 1843 & 3627 & NM_194293 & $3 \mathrm{p} 22.2$ \\
\hline PTPLA & 7 & 288 & 1535 & NM_014241 & 10p12.33 \\
\hline FK506 bp 12 & 4 & 108 & 755 & NM_000801 & 20p13 \\
\hline$S C R I B$ & 30 & 1655 & 13492 & NM_015356 & $8 \mathrm{q} 24.3$ \\
\hline GSK3B & 12 & 433 & 3000 & NG_012922 & $3 \mathrm{q} 13.33$ \\
\hline WNT5b & 4 & 359 & 1310 & NM_030775 & $12 \mathrm{p} 13.33$ \\
\hline WNT5a & 5 & 380 & 1562 & NM 003392 & $3 p 14.3$ \\
\hline WNT11 & 5 & 354 & 1367 & NM_004626 & $11 q 13.5$ \\
\hline SFRPI & 3 & 314 & 1157 & NM_003012 & 8p11.21 \\
\hline SFRP3 & 6 & 325 & 1748 & NG_017197 & $2 q 32.1$ \\
\hline MAPK1 (ERK2) & 8 & 360 & 2072 & NC_000022 & $22 q 11.2$ \\
\hline SERCA2 & 20 & 1042 & 5169 & NG_007097 & $12 q 24.11$ \\
\hline NCXI(SLC8AI) & 7 & 937 & 4021 & NC_000002 & $2 \mathrm{p} 22.1$ \\
\hline CABIN1 & 35 & 2141 & 10093 & NC_000022 & $22 q 11.23$ \\
\hline Total & 1691 & 109802 & 503340 & & \\
\hline
\end{tabular}

*Genes also analyzed by long-range polymerase chain reaction followed by massively parallel sequencing. 
the time of study initiation were included. The 110 genes and their encoded proteins are involved in sarcomere, cytoskeletal, or desmosome organization, fatty acid oxidation, carnitine transport, storage disorders, syndromic phenotypes, and mitochondrial organization. These genes have previously been reported as disease-causing in distinct human cardiomyopathy phenotypes.

\section{Long-range PCR and DNA pooling}

For PCR-based enrichment, genes of interest were divided into 84 long-range amplicons to provide coverage to all coding regions and splice-junctions. The custom design aimed to minimize the number of amplicons and generate a majority of amplicons ranging from $3 \mathrm{~kb}$ to $10 \mathrm{~kb}$. As a result, the majority of introns less than $4 \mathrm{~kb}$ were covered in their entirety. Primer sets were designed using Primer3 program (sequences available upon request). PCR amplifications were performed in a $30 \mu \mathrm{L}$ reaction mixture using $20 \mathrm{ng}$ DNA, 20 pmoles of each primer, $400 \mu \mathrm{M}$ dNTPs, and 3 units of LA Taq polymerase in 1x LA PCR buffer (Takara Inc., Japan). Thermocycling included an initial denaturation for $3 \mathrm{~min}$ at $94^{\circ} \mathrm{C}$ followed by 34 cycles of denaturation at $94^{\circ} \mathrm{C}$ for $30 \mathrm{~s}$, annealing and extension at $68^{\circ} \mathrm{C}$ for 3,6 or $10 \mathrm{~min}$ depending on amplicon length, and a final extension at $72^{\circ} \mathrm{C}$ for $8 \mathrm{~min}$. PCR products were purified using QIAquick PCR purification kit (Cat \# 28106, QIAGEN Sciences), quantified by Nanodrop and pooled in an equimolar fashion based on DNA concentration and amplicon size.

\section{Cardiomyopathy capture array}

Custom SeqCap 385K human arrays were designed to our specifications and manufactured by Roche NimbleGen (Madison, WI, USA) by printing 60-mer oligonucleotide probes complementary to the genomic sequences of the coding regions and splice sites of 110 candidate genes (NCBI build 36.1, hg18) onto glass slides. A total of 1505 target regions containing 384,000 probes were tiled onto arrays after exclusion of repetitive sequences. Supplementary Table 1 shows that $99.9 \%$ of targeted nucleotides are represented on the arrays.

\section{Library preparation}

Five genomic libraries (for SeqCap arrays) and 3 LR-PCR libraries (after PCR enrichment and pooling) were prepared for massively parallel sequencing in an identical fashion according to the manufacturer's recommendations (Illumina Inc. San Diego, CA, USA). Briefly, $5 \mu \mathrm{g}$ of DNA (from genomic DNA or 84 pooled long-range PCR products) was fragmented by nebulization for 6 min using 38psi nitrogen gas. Fragments were concentrated and ligated to adaptors from the Illumina Paired-End Library construction kit. After separation by $2 \%$ agarose gel electrophoresis, the $300 \mathrm{bp}$ ( $\pm 25 \mathrm{bp}$ ) fraction was gel cut and purified using QIAquick gel purification kit (Cat \# 28706, QIAGEN Sciences). Library construction was completed by enriching the size selected fragments through 18 cycles of PCR. At this stage, LR-PCR libraries are ready to sequence while SeqCap libraries will be enriched further after array hybridization and elution.

\section{Enrichment of genomic libraries by SeqCap}

Five massively parallel sequencing libraries from 3 patients (CM0001, CM0006 and CM0002, including 3 technical replicates) were generated from genomic DNA and hybridized to NimbleGen custom SeqCap microarrays for targeted enrichment. After elution from arrays, an additional enrichment PCR was performed for these libraries. The manufacturer's recommended protocol was modified as follows: i) $1 \mu \mathrm{g}$ ( $\sim 4$ mole $)$ of library was used in the hybridization; and ii) supplemented with 300 mole (75x excess) each of Illumina primers PE1.1 and PE2.1; iii) after $\mathrm{NaOH}$ based elution of captured library molecules, 18 cycles of PCR were performed.

\section{Massively parallel sequencing}

Massively parallel sequencing of the SeqCap array enriched genomic libraries or LR-PCR libraries (Table 2) was carried out on the Illumina Genome analyzer IIx according to the manufacturer's protocol as single end 35- and 50-bp reads or as paired end (PE) 72-bp reads. One lane of an Illumina flow cell was used for each SeqCap sample whereas 3 LR-PCR amplified samples were run in groups of 10 per lane (pooled samples with 10 different DNA barcodes including 7 other unrelated samples to this study). All sequence reads were mapped to the reference human genome (UCSC hg 18) using the Illumina Pipeline software version 1.5 featuring a gapped aligner (ELAND v2). For variant identification downstream of CASAVA, the bioinformatics and sequencing core at CCHMC uses a validated custom, post-alignment software for read-sequence visualization and analysis called SeqMate (P Putnam, unpublished data, 2011). The tool combines the aligned reads with the reference sequence and computes a distribution of call quality at each aligned base position taking into account strand bias. Variants are reported on the basis of a configurable formula. For the custom arrays, the following settings were used: 10x minimum coverage, quality score (Phred) greater than 25 , heterozygote allelic ratios allowed from $50 \% / 50 \%$ to $75 \% / 25 \%$, and a minimum of 3 distinct reads per location per base call. All variants were searched in dbSNP135 and 1000 genomes project (June 2011). Amino acid changes were identified by comparison with the UCSC RefSeq database track.

\section{Sanger sequencing validation}

Non-synonymous coding SNPs (cSNPs) and
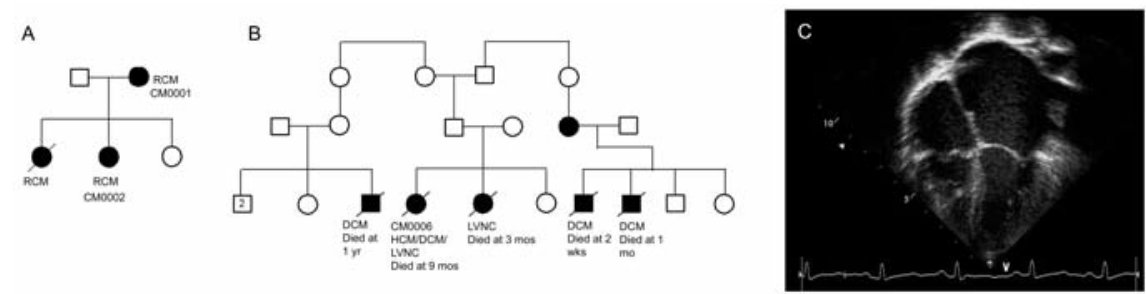

Figure 1. (A, B) Pedigrees of families A and B; (C) Echocardiographic findings of restrictive cardiomyopathy in CM0002.

Table 2. Summary of long-range polymerase chain reaction versus sequence capture based massively parallel sequencing.

\begin{tabular}{lcccccc} 
Method & $\begin{array}{c}\text { Total target } \\
\text { sive (bp) }\end{array}$ & $\begin{array}{c}\text { Total exons } \\
(\mathrm{b} p)\end{array}$ & $\begin{array}{c}\text { Avg total aligned } \\
\text { reads }\end{array}$ & $\begin{array}{c}\text { Avg depth of } \\
\text { coverage }\end{array}$ & $\begin{array}{c}\% \text { exons } \\
\text { avg }>10 x\end{array}$ & $\begin{array}{c}\% \text { exon } \\
\text { bp }>10 x\end{array}$ \\
LR-PCR & 379,285 & 41,486 & 751,512 & $71 x$ & 90.04 & 89.1 \\
SeqCap & 623,783 & 328,498 & $4,223,998$ & $442 x$ & 99.65 & 99.73 \\
\hline
\end{tabular}

LR-PCR, long-range polymerase chain reaction; SeqCap, sequence capture; Avg, average. 
a splice-site mutation detected by SeqCap and PCR-enrichment were validated by Sanger sequencing. Primer sets for exons of interest were designed flanking the nucleotide change using ExonPrimer perl script available at Genome Browser UCSC homepage and Primer3 program. More than 9000 bases targeted by both platforms were sequenced by Sanger sequencing and results were analyzed via Bioedit sequence alignment editor, version 6.0.7. Primer sequences, amplicon size, and PCR conditions for individual cSNPs are available upon request.

\section{Illumina Quad-Omni array}

Samples were genotyped using the Illumina Infinium Omnil SNP array using standard methods. 1045 markers intersect with the region captured by the custom arrays and 310 markers are located within the LR-PCR products (Table 3).

\section{In silico functional assessment}

The functional pathogenicity of all non-synonymous cSNPs was analyzed using the bioinformatic tools Polyphen, PANTHER, and SIFT (See Supplementary Methods S1).11-14 Novel cSNPs predicted as pathogenic by one program were considered mutations. Rare variants present in dbSNP at a frequency of less than 0.05 and predicted as pathogenic by two bioinformatic programs were also considered mutations.

\section{Results}

\section{Clinical findings}

Two familial cases of cardiomyopathy were selected for genetic analysis. Pedigree A (Figure 1) shows 2 patients, CM0001 and CM0002, with restrictive cardiomyopathy (RCM) inherited as an autosomal dominant trait. CM0002, now 8 years of age, was diagnosed with RCM at the age of 4 years when she developed echocardiographic evidence of biatrial enlargement (left atrial z-score 4.13, Figure 1C) and diastolic dysfunction. Cardiac catheterization subsequently confirmed the diagnosis. Genetic testing for $M Y B P C 3, M Y H 7$, TPM1, MYL2, MYL3, ACTC1, TNNT2, and TNNC1 genes was performed as part of the clinical diagnostic evaluation. Results showed no pathogenic mutation. CM0001 developed arrhythmia and diastolic dysfunction at the age of 16 years and was diagnosed with RCM after her first pregnancy. The oldest child died at the age of 8 years (status post transplantation for RCM).

Pedigree B (Figure 1) is consistent with an autosomal recessive inheritance pattern in a family of Amish descent. CM0006 was diagnosed with hypertrophic cardiomyopathy and probable left ventricular non-compaction (LVNC) at 5 months of age (LV diastolic septal thickness z-score 7.18; M-mode LV mass 8.17). The proband's sister died from LVNC with heart failure at 3 months. Her clinical course was complicated by tricuspid atresia. The proband showed an undulating cardiac phenotype with dilation and poor cardiac function. The patient met modified Walker criteria, a strict clinical scoring system, for mitochondrial disease. The patient had lactic acidosis. A skin biopsy sent for electron transport chain analysis showed markedly elevated citrate synthase activity, consistent with mitochondrial proliferation. Deficiencies in complexes I, III and IV were detected. The degree of deficiency was marked, especially given that the sample was from skin fibroblasts rather than muscle. CM0006 had clinical testing for one gene known to cause autosomal recessive mitochondrial disorders, SCO2. No mutation was identified. The family declined additional clinical or research testing. The patient died at the age of 9 months.

\section{SeqCap and molecular genetic analysis}

A SeqCap based hybridization approach was used to investigate 110 genes causing cardiomyopathy (Table 1). While mutations in sarcomeric and cytoskeletal genes have been well documented, mutations in metabolic genes are known to cause disease but prevalence is unknown. A custom $385 \mathrm{~K}$ NimbleGen array provided $99.9 \%$ coverage of the exons of interest and hybridization was followed by massively parallel sequencing. On average, 4,223,998 mappable, aligned reads were generated for the custom array (PE, 72 bp) (Supplementary Table 1). The average exon depth of coverage was 442x. Alignment and coverage depth was visualized using a novel graphical user interface (Supplementary Figure 1). Read depth is a very important parameter for making accurate SNP calls. We set a 10x depth of coverage, a minimum for reliable calls. On average, $99.73 \%$ of exon bases were greater than or equal to $10 \mathrm{x}$ coverage with only 897 bases of a total 328,498 protein coding bases lacking sufficient depth for reliable calls (Supplementary Table 1).

The quality of the hybridization based approach and sequencing was assessed using four approaches to determine reproducibility, false positive and false negative rates. Three technical replicates using sample CM0002 showed high reproducibility with base pair coverage less than $10 \mathrm{x}$ occurring in $0.27 \%$, $0.55 \%$, and $0.36 \%$ (Supplementary Table 2). Somewhat surprisingly, increasing the overall depth of coverage did not correlate with increased comprehensive coverage at the base pair level, as the replicate with the highest overall depth of coverage (CM0002-2, 1105x exon coverage) had the lowest rate of coverage greater than 10x across all exon base pairs (99.45\%). Second, we compared our results using the hybridization-based platform to a PCR enrichment approach (LR-PCR) for 31 of

Table 3. Comparison of coding single-nucleotide polymorphism identified by Illumina whole genome genotyping versus massively parallel sequencing (long-range polymerase chain reaction and sequence capture).

\begin{tabular}{|c|c|c|c|c|c|}
\hline \multirow{2}{*}{$\begin{array}{l}\text { Method } \\
\text { LR-PCR }\end{array}$} & \multirow[t]{2}{*}{ Total shared cSNPs* } & \multirow[t]{2}{*}{$\%$ Concordance } & \multicolumn{3}{|c|}{ Discordant cSNPs } \\
\hline & & & Het loss $^{\circ}$ & Het gain\# & Allele switch ${ }^{\S}$ \\
\hline Covg $>5 \mathrm{x}$ & 532 & 99.62 & 1 & 1 & 0 \\
\hline $\operatorname{Covg}>10 x$ & 504 & 100 & 0 & 0 & 0 \\
\hline Covg $>20 x$ & 463 & 100 & 0 & 0 & 0 \\
\hline \multicolumn{6}{|l|}{ SeqCap } \\
\hline Covg $>5 x$ & 2966 & 99.43 & 10 & 6 & 1 \\
\hline Covg $>10 \mathrm{x}$ & 2944 & 99.49 & 8 & 6 & 1 \\
\hline $\operatorname{Covg}>20 \mathrm{x}$ & 2888 & 99.51 & 7 & 6 & 1 \\
\hline
\end{tabular}

LR-PCR, long-range polymerase chain reaction; cSNPs, coding single-nucleotide polymorphisms; SeqCap, sequence capture; Het, heterozygous; Covg, coverage. *Number of nucleotide positions genotoyped by Illumina whole genome SNP array that are also present in the indicated LR-PCR or SeqCap sequencing platforms. ${ }^{\circ}$ Het loss is defined as a heterozygous position (e.g. A/C) identified by Illumina genotyping that is identified as homozygous by massively parallel sequencing; ${ }^{\circledR}$ Het gain is defined as a homozygous position (e.g. A/A) identified by Illumina genotyping that is identified as heterozygous by massively parallel sequencing; ${ }^{8}$ Allele switch is defined as discrepant SNP calls between Illumina genotyping and massively parallel sequencing (e.g A/C vs $\mathrm{G} / \mathrm{T})$. 
110 genes for all samples (Tables 1 and 2) and to Sanger sequencing for 9 genes for 2 samples. Comparison of the LR-PCR approach (Supplementary Table 3) with the SeqCap approach indicates that the areas with low depth of coverage $(<10 \mathrm{x})$ are distinct (data not shown), suggesting a platform specific basis. Third, we performed whole genome genotyping of samples CM0001, CM0002, and CM0006 using the Illumina Infinium Omnil array and compared base calls at SNPs shared with those identified via resequencing. Concordance rate provides an overall assessment of specificity. Since the majority of pathogenic mutations are rare cSNPs, the heterozygous loss rate (SNPs identified by Illumina genotyping but not by massively parallel sequencing approaches) provides an estimate of false negatives whereas the heterozygous gain provides an estimate of false positives. Concordance rates between our variant calling algorithm and the SNP microarray position calls are indicated in Table 3 . Taken together with the overall concordance, the results are consistent with over $99 \%$ sensitivity and specificity. Fourth, we performed Sanger sequencing of non-synonymous cSNPs identified by SeqCap and LR-PCR approaches and validated $98.64 \%$, again consistent with a very low false positive rate.

\section{Analysis of mutations}

To distinguish potentially pathogenic DNA mutations from synonymous and other variants, we focused on non-synonymous cSNPs. A total of 3813 SNPs were detected by SeqCapmediated massively parallel sequencing, including 479 coding changes in all 3 patients (Figure 2). Of these, 75 were present in dbSNP (in total 148 in 3 patients; Supplementary Table 4) and 14 were novel (in total 17 in 3 patients; Supplementary Table 5). In CM0001 and CM0002 from pedigree A, a previously described heterozygous mutation, p.A213V, was identified in DES gene using both SeqCap and LR-PCR platforms. In CM0001, 7 additional novel cSNPs were identified including 3 predicted to be potentially damaging (p.K435N in the XIRP1 gene; p.T1351P and p.G1833W in the CABIN1 gene; Supplementary Table 5). In CM0002, two additional cSNPs were identified.

In CM0006, a homozygous splice site mutation in the MYBPC3 gene $(c .3330+2 \mathrm{~T}>\mathrm{G})$ was identified on both SeqCap and LR-PCR platforms (Table 4). This mutation has previously been described in the Amish population. ${ }^{15}$ Furthermore, two predicted pathogenic novel cSNPs, p.V134A and p.P31A, were detected in
NDUFV2 and NDUFAF4, respectively on the SeqCap platform. The NDUFAF4 p.P31A mutation was not identified in more than 200 control chromosomes in a mitochondrial clinical diagnostic laboratory (Lee-Jun Wong, personal communication, 2011). The SeqCap platform also identified a novel cSNP, p.R1346W, in the MYH6 gene in CM0006. Mutations in this gene have been reported in patients with atrial septal defects ${ }^{16}$ and idiopathic or familial dilated cardiomyopathy. ${ }^{17}$

In silico functional prediction of missense mutation effect was performed using PolyPhen, PANTHER, and SIFT programs for all missense mutations (See Supplementary Methods S1). ${ }^{11-14}$ Fifty-four variants were pre-

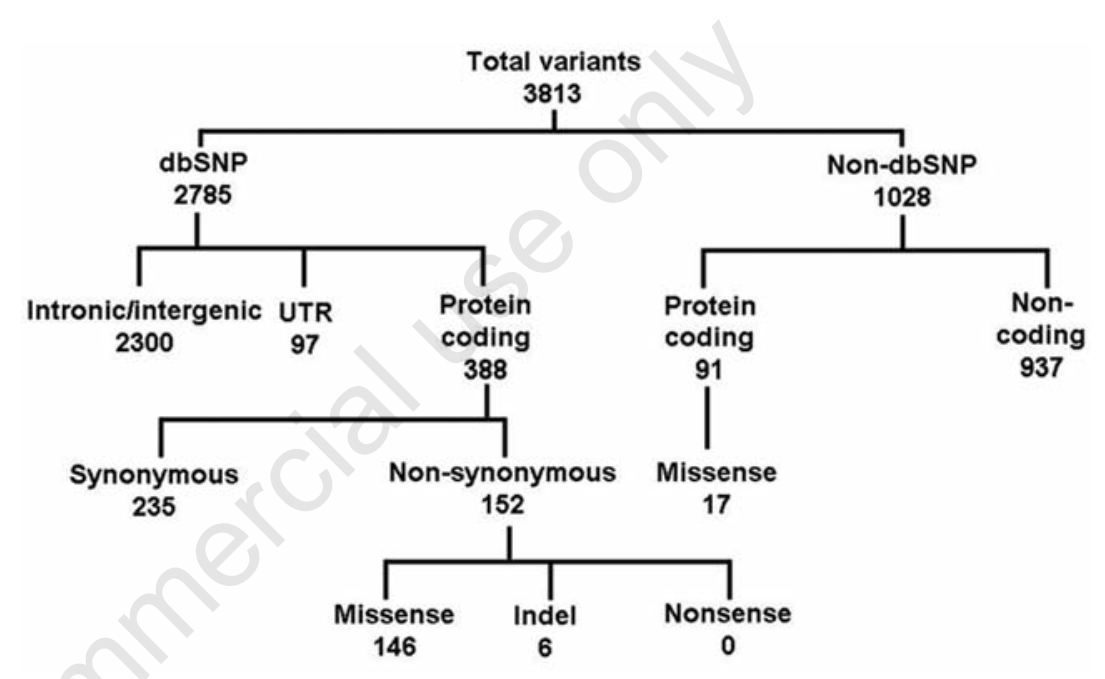

Figure 2. Summary of the total variants detected by sequence capture based massively parallel sequencing in all 3 patients.

Table 4. Mutations identified in each patient.

\begin{tabular}{|c|c|c|c|c|c|}
\hline Patient ID & Gene & Mutation & MAF & $\begin{array}{c}\text { Predicted } \\
\text { Pathogenicity* }\end{array}$ & $\begin{array}{l}\text { Previously reported } \\
\text { with a disease }\end{array}$ \\
\hline CM0001 & $\begin{array}{c}\text { DES } \\
\text { GBE1 } \\
\text { XIRP1 } \\
\text { CABIN1 } \\
\text { CABIN1 }\end{array}$ & $\begin{array}{l}\text { p.A213V } \\
\text { p.V334I } \\
\text { p.K435N } \\
\text { p.T1351P } \\
\text { p.G1833W }\end{array}$ & $\begin{array}{c}\mathrm{N} / \mathrm{A} \\
0.017 \\
\mathrm{~N} / \mathrm{A} \\
\mathrm{N} / \mathrm{A} \\
\mathrm{N} / \mathrm{A}\end{array}$ & $\begin{array}{l}+++ \\
+++ \\
+++ \\
+++ \\
+\end{array}$ & $\begin{array}{l}\text { Yes } \\
\text { No } \\
\text { No } \\
\text { No } \\
\text { No }\end{array}$ \\
\hline CM0002 & $\begin{array}{c}\text { DES } \\
\text { GBE1 } \\
\text { PYGM }\end{array}$ & $\begin{array}{l}\text { p.A213V } \\
\text { p.V334I } \\
\text { p.A365V }\end{array}$ & $\begin{array}{c}\mathrm{N} / \mathrm{A} \\
0.017 \\
\mathrm{~N} / \mathrm{A}\end{array}$ & $\begin{array}{c}+++ \\
+++ \\
++\end{array}$ & $\begin{array}{l}\text { Yes } \\
\text { No } \\
\text { Yes }\end{array}$ \\
\hline CM0006 & $\begin{array}{c}\text { NDUFV2 } \\
\text { GBE1 } \\
\text { XIRP1 } \\
\text { NDUFAF4 } \\
\text { MYH6 } \\
\text { MYBPC3 }\end{array}$ & $\begin{array}{c}\text { p.V134A } \\
\text { p.V334I } \\
\text { p.Q754P } \\
\text { p.P31A } \\
\text { p.R1346W } \\
\text { c. } 3330+2 \mathrm{~T}>\mathrm{G}\end{array}$ & $\begin{array}{c}\text { N/A } \\
0.017 \\
\text { N/A } \\
\text { N/A } \\
\text { N/A } \\
\text { N/A }\end{array}$ & $\begin{array}{c}++ \\
+++ \\
++ \\
+++ \\
++ \\
\text { Altered splicing }\end{array}$ & $\begin{array}{l}\text { No } \\
\text { No } \\
\text { No } \\
\text { No } \\
\text { No } \\
\text { Yes }\end{array}$ \\
\hline
\end{tabular}

MAF, Minor allele frequency (HapMap/CEU); N/A, Not identified in 226 ethnically matched control alleles. *PolyPhen, SIFT, and PANTHER were used to assess pathogenicity. Each program that predicted a deleterious change is designated with + . See Supplementary Tables 4 and 5 for full details. 
dicted as pathogenic by at least one bioinformatic tool (Figure 3) and 27 of these were predicted as pathogenic by more than one program, increasing the likelihood of functional significance. On average, each patient has 4 cSNPs predicted to be deleterious (Table 4). Figure 4 illustrates that amino acid residues altered in missense mutations in NDUFAF4, XIRP1, PYGM, CABIN1 and MYH6 are highly conserved across species, arguing for functional significance.

\section{Discussion}

\section{Towards development of a novel cardiomyopathy SeqCap platform}

Advances in genomic technologies have markedly accelerated the search for genetic causes of human disease and answered previously intractable questions regarding disease mechanisms. In this context, selected genomic regions, genes or exons are targeted by different enrichments methods (e.g. SeqCap, RainDance, Fluidigm) followed by massively parallel and cost-effective resequencing. ${ }^{18-20}$ Although traditional Sanger sequencing remains the gold standard for mutation detection, it is not readily scalable for diseases with significant genetic heterogeneity such as cardiomyopathy. Our results indicate the utility of a novel custom cardiomyopathy chip for identification of rare variants and disease causing mutations. This custom array hybridization approach was efficient and less time consuming and costly compared to PCR amplification and Sanger sequencing of the same genes.

Analytical validity and clinical validity are two important metrics for genetic testing within a diagnostic laboratory. The SeqCap platform for the analysis of 110 genes in a single reaction showed excellent analytical validity, with $99.73 \%$ of base pairs called and over $99 \%$ sensitivity and specificity. There were few regions with less than adequate coverage. In clinical testing, increases above $99.73 \%$ call rates could potentially be achieved with double or triple probe coverage in regions known to be problematic for capture. In addition, it is likely that improvements in bioinformatic alignment programs and technical improvements in the SeqCap technology and massively parallel sequencing output will lead to overall improved technical performance in the future. While whole-exome and whole-genome sequencing are becoming increasingly affordable, one advantage of a more restricted panel of genes for clinical testing is the less problematic interpretation and improved clinical validity. Finally, the LR-PCR based approach, with $89.1 \%$ base pair coverage, does not meet analytical requirements for a clinical test.

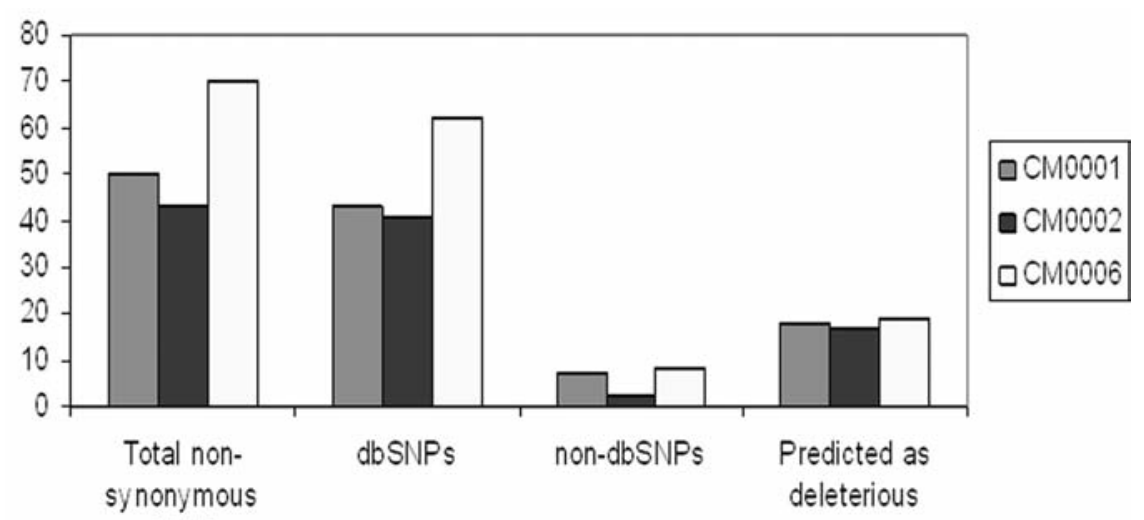

CSNPS

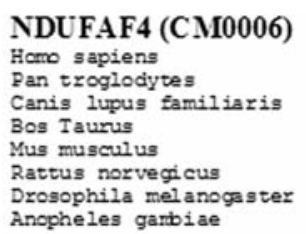

XIRPl (CM0001)

Horno sapiens

Canis lupus familiaris

Bos Taurus

Mus musculus

Rattug norvegicus

\section{PY GM (CM0002)}

Homo sapiens

Pan troglodyte

Canis lupus familiaris

Bos Taurug

Mus musculus

Rattus norvegicus

Danio rerio

Drosophila melanogsate:

Anopheles ganbiae

Caenorhabditis elegans

\section{CABINl (CM0001)}

\section{Hono sapiens}

Pan troglodytes

Canis lupus familiaris

Mus musculus

Rattus norvegicus

Gallus gallus

Danio rerio

\section{CABINl (CM0001) \\ Hono sapiens \\ Pan troglodytes \\ Canis lupus familiaris \\ Mus musculus \\ Rattus norvegicus \\ Gallus gallus}

Danio rerio

\section{MYH6 (CM0006)}

Horn sapiens

Mus musculus

Rattus norvegicus

Gallus gallus

Danio rexio
p.P31A

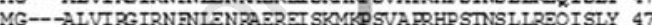

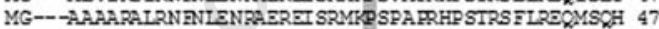
MG---AAVARAVRNDNIENRAER JT SPMRPSPARHP STKNLITIOMSSH 47

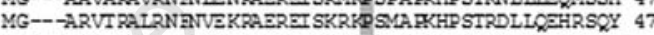
NG---A.RMT RA IRN ANVEKRA Q II SKRKP SMA.RKHP STRSLIQPHLSQY 47

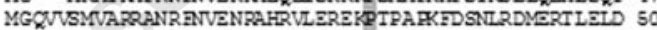
MGKAISVVGRQVRANVENRA CKVI SQAKPKPAKIESILDIERVLKDH 50

\section{p.K435N}

401 HLQRVDPQDGEG---HLSSOSSSAIPFSRSAPRDDIRGDVKIIKNLIE 446 401 HLQRVGPRDHEGLISEHLSRDGSSASHSSSAARDGVKGDVKAIKNLFE 450 401 HLQRVGPEG RITEHLSNADPSAPTLSQGAPGRDGVKGDVKIFKNLFE 450 401 HLQRVGHQEG GLVIECLPSNGT SVIPLSR GVPGIDGIRGDVKIFKNLFE 450 400 HLQRVDHQKG GPVIECLSSNGT SALPLSQGVPGNNGPRGDVKIFKNLIE 449

\section{p.A365V}

317 FGCRDPVRTNEDAIPDKVAIQINDTHPSIAIPEIMRILVDIERMDNDKAV 317 FGCRDVURTNELAF PDKVAIRINDH HPSLAIPEIMRILVDLERDWDKA 317 FGCRDPVRTNEDA FDRVAIRINDTHP STAIPEIMRILVDL ERMWDKA 317 FGCRDPVRT SEDAFPDKVAIQINDIHPSIAIPEIMRI IVDL ERIDWDKA:

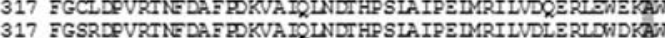
317 FGSRDVVRTIEDA I PKVAIRINDHPSIAIPEIMRILDLERIDWDKAN 317 IGCRDPVRTNGDAIPDKNAIQINDTHPSIAIPEIMRIUVLERIDWDKAi 317 FGSRDIVRTDFSTLPDKVAIRINDHHPAIAIPEIMRVLVEEKLPWEKA 317 FGSREAVRNTI DHFPDKAIQINDTHPSIAIPEIMRIVDEEHLTWEKA 317 FGSRDAVRTSEDDERNKVAIQINDIHPSIAIPEIMRILIDDEKISNEKA

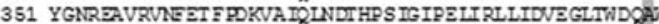

\section{p.T1351P}

1338 PSSSCELTSP PYTAT PIDHDYVICK---------KPHCQATPD-- 1372 1338 PSSSCPGLISP PYTAT PIDHDYVICK--------KPHQQAIPDGT 1374

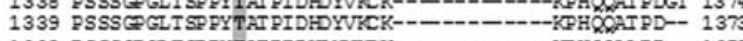
1338 PSSS

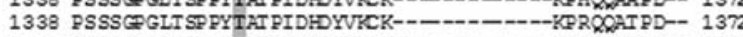
1332 PSSS@ GLTSP PYIATPVDHDYVKK--1336 AGDGAAGASSPYAVI PLDHDYARRKIL $Q R$ RHRQGEQIQRQQQRQQQD- 1383

1803 SISARQQPTILIPAQ----PAPAPAPATTIGTRAGGHP-EEPLSRLSRK 1846 1833 SISARQQPTRLTPAQ--DAPAPAPAPATITGTRAGHP-EEPLSRLSRK 1878 1804 SISAPCQPSILTPAQ-----PALATAPITITGARGGGHP-EELPTRPSRK 1847 1803 SISTRQQPAFLAPSP--AAPTTIAAP-TMAARGAGHS-EEAPPRPNRK 1847 1803 SISTRQRPAFLVPSP--VIP-TIAAP-TINGARAAGHP-EEAPPRPNRK 1846

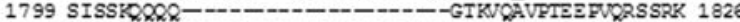
1846 SISTKQQQQXQQQIQNQVNNAAKPATTPITPTPLRS GADI--VVPCRPSRK 1890

p.Rl346 W

1319 RQIZXEGKANALAHAIQSARHDCIIREYEEITEAKAELQRVISKANS 136

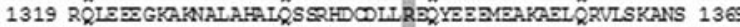

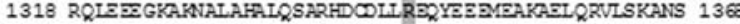

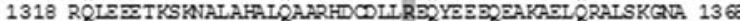

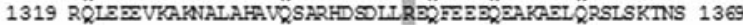

Figure 4. Novel missense mutations identified occur in highly conserved amino acids. Partial amino acid sequence comparisons of human NDUFAF4, XIRP1, PYGM, CABIN1 and MYH6 with other orthologs. The shaded residues indicate high conservation across species. Variations at protein level are shown above each shaded amino acid. 
Nevertheless, we note that this degree of coverage is within the realm of most research based applications and given the high specificity and sensitivity, this approach remains a viable option for research based testing. Overall, the LR-PCR approach was much more labor intensive than SeqCap.

\section{Identification of mutations in car- diomyopathy patients}

The custom array was used to investigate two types of cardiomyopathy in which the molecular basis is not well understood: RCM and mitochondrial cardiomyopathy. RCM is a distinct cardiomyopathy characterized by diastolic dysfunction but intact systolic function until later stages of the disease. RCM accounts for less than 5\% of all cardiomyopathies in the United States and Europe ${ }^{21}$ and the prognosis is particularly poor in children. To date, dominant mutations causing RCM have been reported in DES, ACTC1, TNNI3, TNNT2, and MYH7, but the majority of cases are considered idiopathic. ${ }^{22,23}$ In the present study, we identified the heterozygous mutation p.A213V in DES in the mother and daughter CM0001 and CM0002 from pedigree A. This mutation has been described previously as conditionally pathogenic causing lateonset dilated cardiomyopathy, familial RCM and desminopathy. ${ }^{24,25}$ Desmin (DES) encodes a muscle-specific cytoskeletal protein found in smooth, cardiac, and skeletal muscles. Disease causing mutations have been reported in $D E S$ in dilated cardiomyopathy or desmin-related myopathy. ${ }^{24,25}$

The sample from CM0006 provided the opportunity to investigate the genetic basis of disease in a patient with a complex pedigree and phenotype consistent with mitochondrial disease. Mitochondrial cardiomyopathy is poorly understood at the molecular level. In children, the majority of mitochondrial cardiomyopathies are autosomal recessive and caused by mutations in the nuclear genome rather than the mitochondrial genome. Because many nuclear genes important for mitochondrial function have not yet been identified, molecular diagnosis is challenging. In CM0006, two rare cSNP predicted to be disease-causing were identified in genes encoding proteins important for complex I of the mitochondrial electron transport chain, p.V134A in NDUFV2 and p.P31A in NDUFAF4. NDUFAF4 encodes an assembly factor of mitochondrial complex I and has been previously described in complex I deficiency causing infantile mitochondrial encephalomyopathy and cardiomyopathy. ${ }^{26}$ The functional significance of mutations for two complex I mitochondrial proteins requires further assessment.

Surprisingly, the patient was also found to be homozygous for a previously reported splice mutation in MYBPC3 (c.3330+2T>G). This mutation has been associated previously with a severe neonatal hypertrophic cardiomyopathy in the Amish community when homozygous and hypertrophic cardiomyopathy with incomplete penetrance when heterozygous. ${ }^{15,27,28}$ In addition, a novel cSNP in MYH6 gene was identified that may play a role in the familial cardiomyopathy or history of congenital heart defect based on its published functions. ${ }^{16,17}$ The finding of multiple putative disease-causing alleles in this family may explain the complex inheritance pattern noted in the pedigree. Unfortunately, family members declined further research testing, precluding the possibility of defining segregation with phenotype. Nevertheless, these results indicate the importance of screening multiple genes on a single platform, allowing examination of the potential interplay between genetic alterations in the structural apparatus of the cardiomyocyte and metabolic pathway-specific genes. Further development of these technologies will offer a unique opportunity to interrogate complex patterns of inheritance due to the involvement of more than one gene.

\section{Novel sequencing technology identifies multiple rare variants}

Phenotypic variability is frequently observed in closely related family members carrying the same cardiomyopathy causing mutations. ${ }^{29}$ This phenotypic variability has been attributed to environmental influences (e.g. blood pressure, diet, activity) and the individual's specific genetic background. However, recognition of modifying genetic influences has significantly increased as the identification of diseasecausing genes has expanded.

Recent studies on hypertrophic cardiomyopathy have shown that individuals may have 2 distinct pathogenic mutations. ${ }^{30}$ The identification of more than one mutation in some children with cardiomyopathy has led to the suggestion that early onset is due to a two hit digenic mechanism with case reports indicating that these individuals are younger and have more aggressive disease. ${ }^{31-33}$ However, this view is controversial with some stating that there is insufficient evidence of the functional effects of multiple mutations. ${ }^{34}$ As demonstrated by this study, one of the challenges for clinical laboratories will be the interpretation of the multiple rare or novel cSNPs identified using massively parallel sequencing. In this small study, an average of 4 potential disease-causing cSNPs was identified in each patient. In the past, a final common pathway hypothesis had been proposed to explain similar phenotypes caused by different genes (genetic heterogeneity). This hypothesis suggests that mutated proteins of similar functions or signaling pathways ${ }^{35-37}$ can lead to cardiomyopathy phenotypes that are clinically indistinguishable. This study documents both the technical ability to identify multiple rare variants or mutations in a single patient as well as the challenges of interpretation. In the future, it will be possible to analyze whether multiple rare mutations in the same or different genes act in concert to modulate the disease phenotype.

Whole exome sequencing has recently been successfully applied to identify the genetic basis of rare disorders with very specific clinical features while its application in finding genetic mechanisms for complex human diseases is under development. ${ }^{38-41}$ Results with emerging genomic technologies indicate that approximately 400 novel protein coding variants are identified with full exome sequencing. In addition, bioinformatic programs predict that approximately $20 \%$ of common human non-synonymous SNPs damage the proteins. ${ }^{12}$ Because of this, recognition of rare variants that significantly impact protein function in genetically and phenotypically heterogeneous diseases, such as cardiomyopathy, is challenging. Mutations identified in multiple genes in the present study provide insight into the large number of altered protein-protein interactions, potentially resulting in a combined effect on function. Although bioinformatics programs continue to improve, they do have limitations. For example, the variant p.R1745H in dystrophin is present in the population at a frequency of $43 \%$ but is nevertheless predicted to be deleterious. Use of multiple prediction programs, as in this study, can improve overall prediction but nevertheless cannot prove functional significance. High throughput sequencing technologies provide the technical basis to screen candidate genes or the complete exome in large cohorts of patients, However, the interpretation of the results of these studies will require further development of bioinformatics, mutation prediction, and functional screens. By addressing these issues with interpretation of massively sequencing data we will be able to provide genome-guided diagnosis and treatment.

\section{Study limitations}

Detection of deletions and insertions with the stringency required for clinical testing remains problematic with massively parallel sequencing. Incorporation of probes specific to previously described deletions and insertions associated with cardiomyopathy may be used to overcome this problem. In addition, further development of efficient and robust bioinformatic approaches addressing novel indel variations will aid mutation identification. The 13 cSNPs identified in this study are predicted to be pathogenic (in silico) as missense mutations (Table 4) but additional studies are required to more fully investigate their effect and combined functions. 


\section{Conclusions}

In summary, we have investigated a novel genetic diagnostic platform for pediatric cardiomyopathy using array-based sequence technology followed by massively parallel sequencing. Furthermore, we compared the performance of targeted array-based and long-range PCR based genomic DNA enrichments for massively parallel sequencing and found arraybased enrichment more cost and time efficient and more sensitive. Through this array-based sequencing, 89 different non-synonymous cSNPs and one splice site mutation were identified including multiple predicted diseasecausing variants in each patient. This study highlights the difficulty of interpreting highthroughput sequencing data with a number of predicted pathogenic variants even in a small sequence capture experiment.

\section{References}

1. Mamanova L, Coffey AJ, Scott CE, et al. Target-enrichment strategies for nextgeneration sequencing. Nat Methods 2010;7:111-8.

2. Okou DT, Locke AE, Steinberg KM, et al. Combining microarray-based genomic selection (MGS) with the Illumina Genome Analyzer platform to sequence diploid target regions. Ann Hum Genet 2009;73:502-13.

3. Albert TJ, Molla MN, Muzny DM, et al. Direct selection of human genomic loci by microarray hybridization. Nat Methods 2007;4:903-5.

4. Porreca GJ, Zhang K, Li JB, et al. Multiplex amplification of large sets of human exons. Nat Methods 2007;4:931-6.

5. Ng SB, Bigham AW, Buckingham KJ, et al. Exome sequencing identifies MLL2 mutations as a cause of Kabuki syndrome. Nat Genet 2010;42:790-3.

6. Nikopoulos K, Gilissen C, Hoischen A, et al. Next-generation sequencing of a 40 Mb linkage interval reveals TSPAN12 mutations in patients with familial exudative vitreoretinopathy. Am J Hum Genet 2010; 86:240-7.

7. Volpi L, Roversi G, Colombo EA, et al. Targeted next-generation sequencing appoints c16orf57 as clericuzio-type poikiloderma with neutropenia gene. Am J Hum Genet 2010;86:72-6.

8. Rehman AU, Morell RJ, Belyantseva IA, et al. Targeted capture and next-generation sequencing identifies C9orf75, encoding taperin, as the mutated gene in nonsyndromic deafness DFNB79. Am J Hum Genet 2010;86:378-88.
9. Raca G, Jackson C, Warman B, et al. Next generation sequencing in research and diagnostics of ocular birth defects. Mol Genet Metab 2010;100:184-92.

10. Summerer D, Schracke N, Wu H, et al. Targeted high throughput sequencing of a cancer-related exome subset by specific sequence capture with a fully automated microarray platform. Genomics 2010;95: 241-6.

11. Kumar P, Henikoff S, Ng PC. Predicting the effects of coding non-synonymous variants on protein function using the SIFT algorithm. Nat Protoc 2009;4:107381.

12. Sunyaev S, Ramensky V, Koch I, et al. Prediction of deleterious human alleles. Hum Mol Genet 2001;10:591-7.

13. Thomas PD, Campbell MJ, Kejariwal A, et al. PANTHER: a library of protein families and subfamilies indexed by function. Genome Res 2003;13:2129-41.

14. Thomas PD, Kejariwal A, Campbell MJ, et al. PANTHER: a browsable database of gene products organized by biological function, using curated protein family and subfamily classification. Nucleic Acids Res 2003;31:334-41.

15. Xin B, Puffenberger E, Tumbush J, et al. Homozygosity for a novel splice site mutation in the cardiac myosin-binding protein $\mathrm{C}$ gene causes severe neonatal hypertrophic cardiomyopathy. Am J Med Genet A 2007;143A:2662-7.

16. Ching YH, Ghosh TK, Cross SJ, et al. Mutation in myosin heavy chain 6 causes atrial septal defect. Nat Genet 2005;37: 423-8.

17. Carniel E, Taylor MR, Sinagra G, et al. Alpha-myosin heavy chain: a sarcomeric gene associated with dilated and hypertrophic phenotypes of cardiomyopathy. Circulation 2005;112:54-9.

18. Mondal K, Shetty AC, Patel V, et al. Targeted sequencing of the human $\mathrm{X}$ chromosome exome. Genomics 2011;98: 260-5.

19. Najmabadi $\mathrm{H}, \mathrm{Hu} \mathrm{H}$, Garshasbi $\mathrm{M}$, et al. Deep sequencing reveals 50 novel genes for recessive cognitive disorders. Nature 2011;478:57-63.

20. Jones MA, Bhide S, Chin E, et al. Targeted polymerase chain reaction-based enrichment and next generation sequencing for diagnostic testing of congenital disorders of glycosylation. Genet Med 2011;13:92132 .

21. Felker GM, Thompson RE, Hare JM, et al. Underlying causes and long-term survival in patients with initially unexplained cardiomyopathy. $\mathrm{N}$ Engl $\mathrm{J}$ Med 2000;342:1077-84.

22. Kaski JP, Syrris P, Burch M, et al. Idiopathic restrictive cardiomyopathy in children is caused by mutations in cardiac sarcomere protein genes. Heart 2008;94:1478-84.

23. Ware SM, Quinn ME, Ballard ET, et al. Pediatric restrictive cardiomyopathy associated with a mutation in betamyosin heavy chain. Clin Genet 2008;73: 165-70.

24. Goudeau B, Rodrigues-Lima F, Fischer D, et al. Variable pathogenic potentials of mutations located in the desmin alphahelical domain. Hum Mutat 2006;27:90613.

25. Kostareva A, Gudkova A, Sjoberg G, et al. Desmin mutations in a St. Petersburg cohort of cardiomyopathies. Acta Myol 2006;25:109-15.

26. Saada A, Edvardson S, Rapoport M, et al. C60RF66 is an assembly factor of mitochondrial complex I. Am J Hum Genet 2008;82:32-8.

27. Zahka K, Kalidas K, Simpson MA, et al. Homozygous mutation of MYBPC3 associated with severe infantile hypertrophic cardiomyopathy at high frequency among the Amish. Heart 2008;94:1326-30.

28. Wang H, Xin B. Hypertrophic cardiomyopathy in the Amish community - What we may learn from it. Prog Pediatr Cardiol 2011;31:129-34.

29. Hershberger RE, Cowan J, Morales A, Siegfried JD. Progress with genetic cardiomyopathies: screening, counseling, and testing in dilated, hypertrophic, and arrhythmogenic right ventricular dysplasia/cardiomyopathy. Circ Heart Fail 2009;2:253-61.

30. Kelly M, Semsarian C. Multiple mutations in genetic cardiovascular disease: a marker of disease severity? Circ Cardiovasc Genet 2009;2:182-90.

31. Ingles J, Doolan A, Chiu C, et al. Compound and double mutations in patients with hypertrophic cardiomyopathy: implications for genetic testing and counselling. J Med Genet 2005;42:e59.

32. Lekanne Deprez RH, Muurling-Vlietman $\mathrm{JJ}$, Hruda J, et al. Two cases of severe neonatal hypertrophic cardiomyopathy caused by compound heterozygous mutations in the MYBPC3 gene. J Med Genet 2006;43:829-32.

33. Girolami F, Ho CY, Semsarian C, et al. Clinical features and outcome of hypertrophic cardiomyopathy associated with triple sarcomere protein gene mutations. J Am Coll Cardiol 2010;55:1444-53.

34. Ho CY, MacRae CA. Defining the pathogenicity of DNA sequence variation. Circ Cardiovasc Genet 2009;2:95-7.

35. Towbin JA. The role of cytoskeletal proteins in cardiomyopathies. Curr Opin Cell Biol 1998;10:131-9.

36. Towbin JA, Bowles KR, Bowles NE. 
Etiologies of cardiomyopathy and heart failure. Nat Med 1999;5:266-7.

37. Bowles NE, Bowles KR, Towbin JA. The "final common pathway" hypothesis and inherited cardiovascular disease. The role of cytoskeletal proteins in dilated cardiomyopathy. Herz 2000;25:168-75.

38. Feng BJ, Tavtigian SV, Southey MC, Goldgar DE. Design considerations for massively parallel sequencing studies of complex human disease. PLoS One 2011;6:e23221.

39. Choi M, Scholl UI, Ji W, et al. Genetic diagnosis by whole exome capture and massively parallel DNA sequencing. Proc Natl Acad Sci U S A 2009;106:19096-101.

40. Hedges DJ, Burges D, Powell E, et al. Exome sequencing of a multigenerational human pedigree. PLoS One 2009;4:e8232.

41. Johnston JJ, Teer JK, Cherukuri PF, et al. Massively parallel sequencing of exons on the $\mathrm{X}$ chromosome identifies RBM10 as the gene that causes a syndromic form of cleft palate. Am J Hum Genet 2010;86: 743-8. 